\title{
GILLES DELEUZE E O PENSAMENTO NÔMADE: A MÁQUINA DE GUERRA PRIMITIVA
}

\author{
Carlos Fernando Carrer da Cunha*
}

\begin{abstract}
Resumo:
A filosofia de Gilles Deleuze sempre se realizou em relação estreita com outros domínios do saber e da prática humana, como a literatura, a arte, a ciência, a psicanálise e a política. Nesta breve apresentação, pretendemos discutir alguns aspectos chaves para a compreensão da filosofia deleuziana, para que enfim eles se desdobrem nos temas centrais de nosso projeto de pesquisa, isto é, os pontos de abertura entre a obra do filósofo francês e a etnologia através de uma discussão acerca do conceito de multiplicidade e das funções que ele desempenha junto aos estudos etnológicos contemporâneos. A filosofia de Deleuze (inclusive em seus livros assinados com Félix Guattari) abriga um extenso rol de conceitos - máquina de guerra, nomadismo, devir minoritário, entre outros - que está diretamente associado ao estudo das chamadas "sociedades primitivas", o que torna necessário, em um primeiro momento, traçar uma forma específica de genealogia dos conceitos deleuzo-guattarianos segundo critérios que contemplem as características particulares do empreendimento etnológico. Como parte complementar prevista no projeto de pesquisa, ilustraremos nossas proposições apresentando breves passagens sobre a história das sociedades quilombolas de maneira a contribuir com a pesquisa etnológica enquanto inserida em um cenário filosófico.
\end{abstract}

Palavras-chaves: Deleuze; etnologia; multiplicidade.

Simbolicamente, gosto de pensar que Deleuze jamais teria conseguido escrever seus livros estando assegurado em uma pacífica solidão sob o aconchego de uma lareira, tal como o fez Descartes quando escreveu suas Meditações Metafísicas. É verdade que, em diversas passagens, Deleuze se refere a uma espécie de solidão necessária ao trabalho do filósofo. O professor Peter Pál Pélbart (PUC-SP) conta que, durante uma das aulas de Deleuze no início dos anos 80, um aluno interrompeu e perguntou por que as pessoas eram deixadas sozinhas, dando início a uma lamentação sobre a falta de comunicação da vida moderna, sobre o abandono etc. Pélbart escreveu que, percebendo que a aula iria descarrilar, Deleuze respondeu gentilmente ao aluno antes de propor um intervalo: “o problema não é que nos deixam sós, é que não nos deixam suficientemente sós”. Por um lado, essa sentença pode ser interpretada como uma crítica ao princípio de comunicação,

*Mestrando em Filosofia pela Universidade Federal de São Paulo (UNIFESP). E-mail: carlos.cunha03@gmail.com 
tão fortemente denunciado por Deleuze, que busca estabelecer o consenso entre opiniões, aproximando-se de uma prática niveladora e pouco inventiva, preenchida tão somente por enunciados vazios, comuns. No entanto, esta solidão não deve se confundir com isolamento, especialmente quando tratamos de um filósofo que frequentava cinemas e exposições ou mesmo se predispunha a cooperar com outros pensadores, como no caso de Félix Guattari, seu incessante interlocutor. Em Deleuze, tratamos de um tipo específico de solidão:

"Quando se trabalha, a solidão é, inevitavelmente, absoluta (...). Só que é uma solidão extremamente povoada. Não povoada de sonhos, de fantasmas nem de projetos, mas de encontros (...). É do fundo dessa solidão que se pode dar qualquer encontro. Encontram-se pessoas (e por vezes sem as conhecer nem as ter jamais visto), mas também movimentos, ideias, acontecimentos, entidades. Todas estas coisas têm nomes próprios, mas o nome próprio não designa de modo algum uma pessoa ou um sujeito. Designa um efeito, um ziguezague, alguma coisa que passa ou que se passa entre dois como sob uma diferença de potencial: «efeito Compton», «efeito Kelvin»". 1

Em Deleuze, a condição indispensável para a solidão do filósofo é esta: ela está povoada por afecções intensas derivadas de encontros. Quando trabalha, o filósofo está permeado por aquilo que o afeta, por aquilo que provocou o seu pensamento. É propriamente um pathos, uma paixão externa que mobiliza o pensamento. O filósofo não pensa de boa vontade, mas é um ser à espreita. Em suma, é somente a partir de relações com a exterioridade que o filósofo ganha o que pensar. Assim, Deleuze quer recusar a ideia de um pensamento que se encerra em si próprio, com suas imagens e representações preestabelecidas. É preciso partir de um pensamento sem imagem, um pensamento caracterizado como nômade: não lhe interessa os pontos de chegada ou de partida, mas sim os trajetos que percorre. É neste sentido que podemos falar de uma desterritorialização incessante do pensamento não sobre as essências, mas sobre uma multiplicidade de acontecimentos que saltam do estado de coisas. Em uma sentença, o pensamento nômade é aquele que surge do encontro com o impensável, com o imprevisto, sem que esteja remetido a uma experiência vivida ou representada, mas é conduzido apenas pela criação, pelo advento do novo.

Sendo assim, nossa questão inicial fica como que imantada a outra questão que é apropriado enunciar desde já: a verdade deixa de ser algo a ser encontrado e passa a ser criação; a alma faz parte do corpo e esse é a primeira via de acesso para o pensamento, não um empecilho que o retarda; os métodos rigorosos cedem espaço à cartografia, ao mapeamento de afecções. Esta uma ideia diretriz em Diferença e Repetição que

\footnotetext{
${ }^{1}$ DELEUZE, Gilles. PARNET, Claire. Diálogos. São Paulo: Escuta, 1998, p. 14
} 
constitui o objeto do empirismo transcendental deleuziano, a saber, somente através da elevação do empirismo a um nível transcendental é que nos colocamos em condições de saber os alcances e os limites da criação conceitual, finalidade última da filosofia segundo Deleuze e Guattari. Imergir sobre o empirismo transcendental deleuziano está além dos objetivos pretendidos para esta apresentação. Por ora, devemos reconhecer uma dupla luta, contra o empirismo e o racionalismo tradicionais. Será em Espinosa que Deleuze encontrará uma das influências mais importantes de seu programa: "Em suma: se somos espinosistas, não definiremos alguma coisa pela sua forma, pelos seus órgãos, e suas funções, e nem mesmo como substância ou como sujeito. Empregando termos da Idade Média, ou mesmo da geografia, nós a definiremos pela longitude e latitude"2. Com isso, Deleuze não pretende simplesmente tomar de empréstimo termos aleatórios da geografia, mas propor outro modo de compreender a própria filosofia, como afirma Roberto Machado: "sua característica mais elementar é o fato de ela se propor mais como uma geografia do que propriamente como uma história, no sentido em que, para ela, o pensamento (...), em vez de constituir sistemas fechados, pressupõe eixos e orientações pelos quais se desenvolve". ${ }^{3}$ Finalmente, nossa hipótese matriz é de que a conexão entre a obra de Deleuze e a etnologia é uma das possíveis maneiras de confirmar essa "relação constitutiva da filosofia com a não-filosofia (...)"4, prefigurando o caráter mais essencial de tudo o que fora dito a respeito da (geo)filosofia dos encontros.

No Tratado de nomadologia: a máquina de guerra, serão as concepções do pensamento enquanto "caminho" para atingir a verdade e também como produtor de consensos (tendo o logos como fundamento, ou seja, o exercício compartilhado do discurso e da razão) que constituem as duas "cabeças" do que Deleuze e Guattari chamarão de "Estado". Neste contexto, vale ressaltar que o Estado adquire uma nova significação para além de suas conotações usuais: ele é antes um tipo, uma figura do que propriamente o resultado de avanços civilizatórios, de maneira que, onde lemos Estado, poderíamos ler forma-Estado. "É preciso dizer que o Estado sempre existiu. Quanto mais os arqueólogos fazem descobertas, mais descobrem impérios (... $)^{5 \%}$. Com isso, o Estado deixa de ter uma origem histórica e passar a fazer parte das sociedades na forma de virtualidade imanente, ora encarnando-se enquanto "aplicação de um princípio de

\footnotetext{
${ }^{2}$ DELEUZE, Gilles. Espinosa: filosofia prática. São Paulo: Escuta, 2002, p.132.

${ }^{3}$ MACHADO, Roberto. Deleuze e a filosofia. Rio de Janeiro: Graal, 1990, p. 9.

${ }^{4}$ DELEUZE, Gilles. GUATTARI, Félix. O que é a filosofia? $3^{\mathrm{a}}$ edição. São Paulo: Ed. 34, 2010, p.132

${ }^{5}$ DELEUZE, Gilles. GUATTARI, Félix. Mil Platôs: capitalismo e esquizofrenia. Vol.5. Rio de Janeiro: Ed. 34, 1997, p.23.
} 
identificação, de um projeto de redução do outro no mesmo"6, ora sendo conjurado por meio dos agenciamentos lineares que se desterritorializam por linhas de fuga (a máquina de guerra).

A noção de "guerra primitiva" em Pierre Clastres tem um peso decisivo na dinâmica conceitual dos dois volumes de Capitalismo e esquizofrenia (especialmente em Mil Platôs), sendo necessário compreender a posição do etnólogo de maneira mais precisa. Em seu argumento, Clastres irá refutar basicamente três visões preestabelecidas concernentes ao motivo da guerra primitiva: 1) naturalista, 2) economista e 3) relativo à troca. Para a primeira, Clastres contesta a teoria de Leroi-Gourhan, cuja ideia central é de que a guerra primitiva nada mais é do que uma repetição do instinto caçador. Clastres, no entanto, observa que a guerra está ligada não a uma questão de necessidade, mas a um tipo de agressividade espontânea. Existem motivações diferentes, quer se considere a caça, quer a guerra. No segundo caso, parte-se da prerrogativa de que as sociedades primitivas eram (ou são) sociedades de miséria e, dada a escassez, as tribos guerreavam entre si para competir pelos bens. A divisão do trabalho, assinala Clastres, permitia aos primitivos, pelo contrário, serem "sociedades de lazer" e que não produziam mais do que o necessário. "Os selvagens produzem para viver, não vivem para produzir"7. Por fim, o etnólogo refuta a teoria levi-straussiana de que as guerras eram fruto de trocas mal sucedidas, pois o trabalho etnográfico de Clastres constatou a universalidade da guerra, independentemente do sucesso ou fracasso das relações de troca. Resta dizer: a guerra é uma máquina de geração de multiplicidade, utilizada para assegurar a dispersão dos grupos e conjurar a formação do Estado - definido, segundo Clastres, como "a força atuante do Um, a vocação de recusa do múltiplo, o temor e o horror da diferença"».

No Tratado de Nomadologia, tal tese se estende por uma nova dimensão: a máquina de guerra não tem necessariamente por objeto a guerra. Aqui reencontramos o caráter mais essencial do pensamento nômade: a guerra contra a forma-Estado deve ser incessante, deve fazer valer a carga semântica contida no termo máquina. Ora, isso requer toda uma produtividade, toda uma ação. Em suma, uma criação que pode e deve se encarnar em coisas para além da guerra: um pensamento, uma obra artística, uma invenção da ciência e até mesmo uma ação política. "As mutações remetem a essa máquina, que certamente não tem a guerra por objeto, mas a emissão de quanta de

\footnotetext{
${ }^{6}$ CLASTRES, Pierre. Arqueologia da Violência. $2^{\mathrm{a}}$ edição. São Paulo: Cosaf \& Naify, 2011, p.85

${ }^{7}$ Idem, ibdem, p. 172

${ }^{8}$ Idem, ibdem, p. 83
} 
desterritorialização, a passagem de fluxos mutantes (toda criação nesse sentido passa por uma máquina de guerra)"9

Mas mais precisamente, de que se trata a multiplicidade, tema de nosso projeto, e por que ela é tão importante para compreender o pensamento deleuziano? Decerto, Deleuze não foi o primeiro a trazer este problema para o seio da filosofia. Em primeiro lugar, devemos compreender a multiplicidade enquanto crítica direcionada à dialética dos pretendentes no platonismo ${ }^{10}$ e à dialética dos opostos do sistema hegeliano ${ }^{11}$. Com efeito, a multiplicidade, também denominada "simulacro" em Diferença e Repetição e Lógica do Sentido, sequer participa do método hierárquico da divisão e tampouco assume uma forma de tese ou antítese (Uno x Múltiplo); ela deve ser tomada como substantivo, como uma cadeia infinita de relações (rizoma ${ }^{12}$ ) onde a afirmação de diferença "constitui o próprio ser, nos faz concebê-lo (...), individualizando e determinando as matérias em que se encarna"13.

A multiplicidade é via que nos lança para o plano de pensamento em Deleuze. Inventase assim uma nova ontologia: a univocidade do ser não significa identidade plena, mas ela é, "ao mesmo tempo, distribuição nômade e anarquia coroada"14. Como estabelecer qualquer espécie de hierarquia ou imobilidade dos seres se todos eles são multiplicidades, relações de diferenças intensivas em forma de devir? O fator comum aos seres - daí sua univocidade - é justamente afirmar sua diferença que, ao atingir sua máxima expressão, só pode ser repetida, submetida à prova do eterno retorno: o eterno retorno da diferença. Como escreve Regina Schöpke ${ }^{15}$, "univocidade, na verdade, significa que todos os seres se dizem de uma mesma maneira e num único sentido. Uma só 'voz' para todos os seres... E uma só voz que diz não à identidade, enquanto afirma a diferença e o devir".

Tudo o que foi dito pode agora ser retomado em outro plano: sendo pensada enquanto multiplicidade, a diferença vem a ser a via pela qual o estudo etnológico contemporâneo se desenvolve, buscando as singularidades culturais em suas relações de exterioridade e não em propriedades intrínsecas. Eis o motivo pelo qual Michel Foucault coloca a

\footnotetext{
${ }^{9}$ DELEUZE, Gilles. GUATTARI, Félix. Mil Platôs: capitalismo e esquizofrenia. Vol.4. Rio de Janeiro: Ed. 34, 1996, p.112.

${ }^{10}$ Cf. "Platão e o simulacro". In: Lógica do sentido. $5^{\text {a }}$ edição. São Paulo: Perspectiva, 2009, p.260.

${ }^{11}$ Cf. Bergsonismo (p.37). São Paulo: Editora 34, 1999 e também Foucault (p.25). São Paulo: Brasiliense, 1988.

${ }^{12}$ Cf. Mil Platôs: capitalismo e esquizofrenia. Vol.1. Rio de Janeiro: Ed. 34, 1995, p.12 e 15.

${ }^{13}$ Proust e os signos. $2^{\mathrm{a}}$ edição. Rio de Janeiro: Forense Universitária, 2010, pp. 39-46.

${ }^{14}$ Differénce e Repétition. Paris: PUF, 1968, p.55.

15 "Deleuze e o mundo dos simulacros". Seminário dos alunos do Programa de Pós-Graduação em Filosofia da Universidade Federal do Rio de Janeiro, 1998, p.44
} 
etnologia como uma disciplina contrária aos próprios fundamentos das ciências humanas: ela destitui o primado da identidade, em seu sentido clássico, em favor de um sujeito impessoal e pré-individual. Contra os liames de interioridade e identidade estabelecidos pela forma-Estado, a máquina de guerra primitiva estabelece relações de exterioridade e pode assumir qualquer forma, pois é destituída de valores intrínsecos. É preciso, portanto pensar a máquina de guerra como uma pura forma de exterioridade ao aparelho de Estado, exterioridade imanente, se preferirmos, que aponte para uma potência compreendida enquanto criação, aproximando-se de uma força não mais negativa, mas afirmativa (a pura diferença).

Vimos que, para Deleuze e Guattari, o Estado sempre existiu, o que implica em admitir uma coexistência com a máquina de guerra. Para explicar essa relação, vale evocar a metáfora dos jogos do Tratado de nomadologia: no xadrez, o jogo de Estado, todas as peças têm um valor e movimentos preestabelecidos: o peão sempre caminha em frente e sempre captura na diagonal, as torres sempre se movimentam e capturam nas verticais e horizontais, assim por diante. O go, ao contrário, pode ser jogado com botões, feijões ou equivalentes, e só conseguem capturar as peças do adversário quando são colocadas em relação umas com as outras. Uma só peça, quando colocada de maneira estratégica no tabuleiro, pode capturar diversas peças do adversário. Para enfim compreender essa relação de coexistência, podemos dar seguimento à metáfora de forma extravagante e pensar nos tabuleiros de xadrez e go como duas transparências superpostas e retroprojetadas, eliminando qualquer possibilidade de apreender a máquina de guerra e Estado como duas formas mutuamente exclusivas, tal como apareceria em um sistema dialético à maneira hegeliana.

É preciso muito cuidado neste momento: como escreve Eduardo Viveiros de Castro, “(Em Mil Platôs), a sociedade primitiva de Clastres, que corresponde aos 'Selvagens' do Anti-Édipo, deixa de ser a inventora da 'máquina de guerra' e assim de ser definida por ela" ${ }^{16}$. Não seria possível simplesmente dizer as sociedades primitivas são máquinas de guerra. A relação que devemos buscar entre ambas não é de coextensividade, mas sim de cointensividade. A pergunta pode ser resumida na seguinte fórmula: quais intensidades as sociedades primitivas fazem passar com a máquina de guerra deleuzo-guattariana?

16 “O intempestivo, ainda”. In CLASTRES, Pierre. Arqueologia da Violência. (Posfácio). São Paulo: Cosaf \& Naify, 2011, p. 335. 
Finalmente podemos nos debruçar com mais atenção sobre as sociedades quilombolas. O termo "quilombo", tal como o entendemos hoje, é fruto de inúmeras tentativas de traçar uma definição adequada para um dos maiores símbolos da cultura afro-americana. Para dar um breve em exemplo, em 1994, o Grupo de Trabalho de Comunidades Negras Rurais da Associação Brasileira de Antropologia reuniu-se a pedido do Ministério Público Federal com a finalidade de formular um documento capaz de dar uma definição atualizada ao termo "quilombo" após ter sido reconhecido constitucionalmente pela primeira vez em 1988. O problema de traçar uma definição ao termo em pauta era, nas palavras de Ilka Boaventura Leite, professora da UFSC, "se o quilombo expressaria a dimensão política da identidade negra no Brasil ou se ele seria uma nova redução brutal da alteridade dos diferentes grupos que, sob este prisma, teriam que se adequar a um conceito genérico para novos propósitos de intervenção e controle social" "17. A partir desta breve colocação, levantamos dois problemas de pesquisa a serem possivelmente respondidos: 1) o reconhecimento foi emancipatório ou os quilombos agora devem submeter-se às normas arbitrárias do aparelho de Estado? 2) Que tipo de identidade é essa a qual Ilka Boaventura Leite se refere? Consideremos a seguinte afirmação do professor Kabengele Munanga (USP):

"Pelo conteúdo, o quilombo brasileiro é, sem dúvida, uma cópia do quilombo africano (...). Imitando o modelo africano, eles transformaram esses territórios em espécie de campos de iniciação à resistência, campos esses abertos a todos os oprimidos da sociedade (negros, índios e brancos), prefigurando um modelo de democracia plurirracial que o Brasil ainda está a buscar (...). Apesar de o quilombo ser um modelo bantu, creio eu que, ao unir africanos de outras áreas culturais e outros descontentes não-africanos, ele teria recebido influências diversas, daí seu caráter transcultural. Com efeito, a transculturação parece-me um dado fundamental da cultura afro-brasileira (...). Visavam a formação de identidades abertas, produzidas pela comunicação incessante com o outro, e não de identidades fechadas, geradas por barricadas culturais que excluem o outro" $" 18$.

O quilombo americano será mesmo uma cópia do quilombo africano? Em seu próprio texto, Kabengele Munanga dá a entender que os quilombos estiveram, desde sempre, condicionados pela pluralidade étnica, dotados, invariavelmente, daquilo que ele chamou de "caráter transcultural", donde se segue outro questionamento: a multiplicidade étnica compartilha da mesma natureza que o conceito deleuzoguattariano? Pode ela ser compreendida como um de seus tipos, uma de suas modalidades? Sob este aspecto, poder-se-ia objetar que os escravos iniciaram sua trajetória histórica como forças reativas à ordem escravocrata, e que alguns quilombos (Palmares, principalmente), eram uma tentativa de formar um verdadeiro Estado

\footnotetext{
${ }^{17}$ Os Quilombos no Brasil: questões conceituais e normativas. Revista Etnográfica - Vol. 4, n², 2000.
}

18 "Origem e histórico do quilombo". Revista USP, 28, (1995-6), p.63. 
africano brasileiro ${ }^{19}$. De fato, é inegável que durante um período histórico, "apesar da escravidão, houve certa identificação dos negros com a monarquia" ${ }^{20}$. Contudo, o que mais nos interessa é observar as pretensões de uma formação de um Estado africano no Brasil, isto é, "definir a resistência negra nos quilombos como a negação do regime de cativeiro por meio da criação de uma sociedade alternativa livre" ${ }^{21}$. Afinal, tivemos uma re-ação, cujo fio condutor era a criação de algo novo, criação necessariamente multiplicada, e não apenas pelo fato de terem sido constituídas como identidade aberta, mas também por todas as des/reterritorializações envolvidas, pois, "ao mesmo tempo que africanizavam seu novo mundo, renovavam o que da velha África conseguiram carregar consigo" 22 .

A meu ver, a especificidade desse encontro triangular entre a filosofia de Deleuze, etnologia e sociedades quilombolas nos força a pensar algo novo, algo que ainda não foi apreciado como tal. Como consequência de todas as nossas proposições, buscamos compreender o papel que Deleuze exerce sobre a própria história do pensamento, uma vez que, aparentemente, se torna possível - ou necessário - estabelecer conexões entre a filosofia e tudo que é exterior a ela. Mobilizando máquinas de guerra e pensando à maneira nomadológica, tendemos a encontrar vacúolos onde podemos inventar novas possibilidades de vida para além das determinações régias e dominantes, tornando-nos sujeitos que, como Nietzsche gostaria de dizer, combatem as ideias de seu tempo ao mesmo tempo em saúdam o intempestivo.

\footnotetext{
${ }^{19}$ Cf. os trabalhos de Edison Carneiro e Nina Rodrigues apontados por João José Reis e Flávio dos Santos Gomes na p.11 de Liberdade por um fio: história dos quilombos no Brasil. São Paulo: Cia. das Letras, 1996.

${ }^{20}$ SOARES, Reinaldo da Silva. "Negra nobreza: reis, rainhas e a aristocracia no imaginário negro". Revista USP, n.69, 2006

${ }^{21}$ GOMES, Flávio dos Santos. REIS, João José (org.). Liberdade por um fio: história dos quilombos no Brasil. São

Paulo: Cia. das Letras, 1996, p.13.

${ }^{22}$ Idem, ibidem, p. 11 .
} 